\title{
Comunidade de prática para o uso de materiais didáticos digitais por professores em formação
}

\author{
Katia Alexandra de Godoi ${ }^{1}$, Flaviana dos Santos Silva ${ }^{2}$ \\ ${ }^{1}$ Pontifícia Universidade Católica de São Paulo \\ ${ }^{2}$ Pontifícia Universidade Católica de São Paulo \\ \{katigodoi@gmail.com, flavianadssegmail.com\}
}

\begin{abstract}
The aim of this paper is to present a preliminary study on the creation of a community of practice for the use of digital learning materials with educational laptops for teachers in Continuing Education Project One Computer per Student (UCA). The study was initiated in 2010 and has as a tool Environment Collaborative Learning e-Proinfo. The results show that the creation of the community aroused discussion and reflection on the choice of digital learning materials available on the laptop and Web 2.0.
\end{abstract}

Resumo. $O$ objetivo deste trabalho é apresentar um estudo preliminar sobre a criação de uma comunidade de prática para o uso de materiais didáticos digitais com computadores portáteis por professores na Formação Continuada do projeto Um Computador por Aluno (UCA). O estudo foi iniciado em 2010 e tem como ferramenta o Ambiente Colaborativo de Aprendizagem e-Proinfo. Os resultados mostram que a criação da comunidade suscitou discussão, bem como reflexões sobre a escolha de materiais didáticos digitais disponíveis no computador portátil e Web 2.0.

\section{Introdução}

Ao iniciarmos, em julho de 2010, a atuação como pesquisadoras no projeto Um Computador por Aluno (UCA), vinculado ao Ministério da Educação (MEC), Brasil, nos deparamos com um cenário de formação a distância de aproximadamente 25 professores de uma escola localizada na Região Metropolitana de São Paulo, com o objetivo de promover a apropriação tecnológica e pedagógica para o uso dos laptops educacionais em atividades curriculares.

No decorrer do processo, enquanto os professores participavam do curso de Formação Inicial, denominado Formação Brasil, na modalidade a distância, criávamos uma comunidade de prática, na qual professores e pesquisadores do projeto UCA poderiam compartilhar saberes de sua prática cotidiana, bem como desenvolver estratégias pedagógicas em conjunto para potencializar a apropriação dos computadores portáteis no contexto educacional, assim como a escolha de materiais didáticos digitais.

No desenvolvimento dos módulos do curso, os professores começaram a utilizar as ferramentas de interação e comunicação disponíveis no Ambiente Colaborativo de Aprendizagem e-Proinfo para realizar as atividades on-line. O surgimento de um conjunto de questionamentos de ordens tecnológica e pedagógica foi inevitável. 
Para atender à demanda de aprendizagem a distância e dar respostas aos questionamentos que, muitas vezes, eram totalmente novos, tanto para os professores em formação como para nós, pesquisadoras, fomos impulsionadas a investigar e realizar estudos voltados para a criação de comunidades de prática e também a respeito de materiais no formato digital diretamente relacionados ao uso dos laptops educacionais.

Tal iniciativa apontou para a importância da flexibilidade de aprender com os problemas que emergem a partir do contexto educacional e como estes são norteadores para se estabelecer uma prática pedagógica reflexiva.

Assim, com este artigo, pretendemos apresentar o estudo realizado com base no princípio de criação de comunidades de prática e sobre a importância do uso de materiais didáticos digitais com laptops educacionais, por professores, no projeto UCA.

Inicialmente, trataremos do conceito de comunidade de prática, para então discorrer sobre a escolha de material didático digital. A partir desse referencial teórico, abordamos o método de desenvolvimento da tessitura da comunidade de prática, os resultados embrionários e as considerações possíveis para os desdobramentos da pesquisa.

\section{Comunidade de prática na formação continuada de professores}

O termo comunidades de prática tem sido amplamente aplicado em diferentes situações, desde a gestão de conhecimento de empresas visando à capacitação de funcionários, dentre outras. O conceito foi criado para "caracterizar grupos de pessoas que aprendem juntas". (WENGER, 1996).

Segundo Wenger (1998, p. 36) a "aprendizagem conjunta ocorre ao longo de séculos ou durante a realização de projetos significativos, que inclui identidades das pessoas envolvidas e dão sentido de como podem interagir com o mundo". Para tal, os autores Wenger, McDermott e Snyder (2002) consideram que as comunidades de prática possuem três elementos fundamentais: domínio, comunidade e prática.

O domínio refere-se à essência do compartilhamento de práticas comuns, ou seja, é a confirmação dos objetivos, do sentido, do valor e da identidade dos membros com a comunidade; a comunidade configura-se a partir dos relacionamentos entre os membros, com o propósito de compartilhar conhecimento; e a prática é composta de estratégias de resolver problemas, experiências, histórias, recursos, que serão compartilhados entre os membros.

Assim, a comunidade de prática é constituída por níveis de participação dos membros, classificados como central, ativo e periférico. O central é líder da comunidade, propõe temas e lança desafios; ativo é o membro que possui participação efetiva nas discussões e, em geral, expõe suas experiências naturalmente; e o periférico refere-se aos membros novos na comunidade, que inicialmente observam e aos poucos vão interagindo com os demais membros. Os níveis não são fixos e poderá ocorrer a transição de um para outro.

Deste modo, ser membro de uma comunidade de prática permite não só a construção do conhecimento técnico, ou habilidade associada às atividades realizadas em sua função, mas permitirá um envolvimento significativo, que o tornará responsável por interagir e se relacionar com os membros. (WENGER, 1998). 
Nessa perspectiva, como explorar o potencial de uma comunidade de prática na formação de professores? É possível que, como membro de uma comunidade de prática, o professor consiga introduzir mudanças em seu fazer pedagógico, por meio das reflexões e compartilhamentos de experiências?

A partir desses questionamentos, notamos que é fundamental a realização de estudos voltados para desvelar o potencial das comunidades de prática na formação de professores, considerando que estas favorecem a interação, reflexão, o diálogo, a exposição de ideias e construção do conhecimento.

No contexto educacional, o desenvolvimento de um trabalho coletivo na escola, se considerados os aspectos de colaboração, permite que os professores, ao ensinar o que sabem, se engajem na apropriação mútua de conhecimentos. Assim, as parcerias os tornarão capazes de explorar e descobrir novos caminhos. Para a autora, convivemos melhor com as falhas temporárias quando contamos com a força de parceiros (JOHNSTEINER, 2000).

Com o advento da Web 2.0, é possível afirmar que a colaboração entre os professores pode ser estendida para além dos muros da escola. Atualmente, os professores poderão beneficiar-se de ambientes virtuais, bem como de ferramentas síncronas e assíncronas, disponíveis na rede, em prol de sua formação e profissionalização. Para Comassetto (2006, p. 35), nesses ambientes virtuais "abrem-se novos espaços para trabalhos em parcerias, em pequenos ou grandes grupos, que permitem formas inovadoras de aprendizagem".

Diante do cenário posto, é importante que o professor compreenda e desenvolva estratégias de ensino que incorporem os aspectos colaborativos, a fim de propiciar uma aprendizagem significativa a seus alunos. Trazer para suas aulas as possibilidades tecnológicas disponíveis na Web 2.0, ou materiais didáticos digitais, favorecerá a criação de um ambiente propício para a construção de conhecimentos dos alunos.

Estudos realizados apontam que a escolha do material didático digital integrado a atividades do currículo poderão beneficiar o processo de ensino e aprendizagem. É importante que os professores se sintam aptos para selecionar os materiais didáticos digitais de acordo com o contexto de atuação. Porém, cabe salientar que é necessário que ocorra a oferta de cursos de formação voltados para atender a esse fim.

No item a seguir, é apresentamos um enfoque sobre a importância da escolha de materiais didáticos por professores.

\section{Escolha de material didático digital por professores}

Nos últimos anos, no Brasil, registra-se o crescente surgimento de materiais didáticos digitais (p. ex., softwares educativos, objetos de aprendizagem) voltados para o ensino e a aprendizagem, em diferentes níveis e englobando públicos diversos (TEDESCO, 2004). Apesar de existirem há mais de vinte anos, Lyra, Leitão, Amorim e Gomes (2003) ressaltam que tais materiais didáticos digitais ainda não foram utilizados em todo seu potencial, na prática docente, sendo mínima a sua adoção sistemática e integração das Tecnologias Digitais de Informação e Comunicação (TDIC) às atividades curriculares. Para Almeida e Valente (2011), um dos fatores que contribuíram para que 
isso acontecesse foi o fato de os materiais didáticos digitais utilizados estarem muito distantes do que era tratado em sala de aula.

Além desse panorama, Lyra et al. (2003) comentam que as informações disponíveis sobre os materiais didáticos digitais são limitadas, ou seja, o professor conta com pouco suporte na escolha de materiais didáticos digitais para uso durante $\mathrm{o}$ processo de ensino e aprendizagem. E, de certa forma, a escolha de material didático digital implica diretamente a necessidade de o professor compreendê-lo.

Vale ressaltar que os Parâmetros Curriculares Nacionais (PCN) (1998), por exemplo, preveem que o professor conheça o material didático digital que pretende utilizar para problematizar conteúdos curriculares; reflita sobre as possibilidades de cada material didático digital, em relação aos diferentes momentos de aprendizagem.

A Organização das Nações Unidas para a Educação, a Ciência e a Cultura (Unesco), por meio do documento intitulado Padrões de Competência em TIC para Professores (UNESCO, 2008), o qual tem como objetivo fornecer diretrizes para melhorar as capacidades dos professores nas práticas de ensino por meio das TIC, orienta, por exemplo, que os professores demonstrem diversos pacotes de programa (e/ou applets, aplicativos interativos, objetos de aprendizagem) e descrevam como eles apoiam o entendimento do aluno sobre os conceitos-chave e suas aplicações para solucionar problemas complexos; façam com que os participantes desenvolvam critérios de avaliação e regras para justificar suas escolhas, com base na efetividade em relação ao objeto pretendido.

Observa-se, de modo geral, que ambas as diretrizes - as dos PCN e as da Unesco - servem como orientações gerais sobre como os professores podem fazer uso dos materiais didáticos digitais. Entretanto, não trazem recomendações específicas para que os professores possam escolher esses materiais. Desse modo, o avanço das tecnologias, a cada dia, desafiam professores e pesquisadores a aprofundarem o debate das questões sobre os instrumentos de avaliação do material didático digital.

No item a seguir, descreveremos a criação da comunidade de prática para a formação de professores, com o propósito de incorporarem à prática pedagógica o uso de materiais didáticos digitais no e-Proinfo no Projeto UCA do MEC.

\section{Tessitura a comunidade de prática}

O processo de formação de professores para fazerem uso de materiais didáticos digitais com suporte em uma comunidade de prática no ambiente virtual de aprendizagem eProinfo, foi iniciado em maio de 2011.

Atualmente, participam aproximadamente 15 professores de uma escola da rede pública de ensino do Município de Campo Limpo Paulista, localizado na Região Metropolitana do estado de São Paulo.

A justificativa para tal processo partiu da necessidade de preparar os professores para adquirirem competências que os levassem a integrar o uso do computador portátil em atividades vinculadas ao currículo escolar e no projeto UCA.

O projeto UCA, de âmbito nacional, é realizado nos seguintes estados brasileiros: Ceará, Distrito Federal, Minas Gerais, Paraná, Pernambuco, Rio de Janeiro, 
Rio Grande do Sul, São Paulo, Sergipe, Tocantins. Atualmente, participam do programa pelo menos 2 mil professores que atuam na Educação Básica. O principal objetivo do programa é promover a inclusão digital pedagógica e o desenvolvimento dos processos de ensino-aprendizagem de alunos e professores das escolas públicas brasileiras, mediante a utilização de computadores portáteis denominados laptops educacionais (BRASIL, 2010, p. 1).

Vale ressaltar que está prevista, no projeto UCA, a denominada Formação Brasil (BRASIL, 2009), ou seja, a Formação Inicial, a qual está estruturada em cinco módulos, prevista para acontecer por meio de encontros presenciais e do e-Proinfo:

- Módulo 1: Apropriação Tecnológica ${ }^{1}$;

- Módulo 2: Web 2.0²

- Módulo 3a: Formação de Professores ${ }^{3}$;

- Módulo 3b: Formação de Gestores ${ }^{4}$;

- Módulo 4: Elaboração de Projetos ${ }^{5}$;

- Módulo 5: Sistematização da Formação na Escola ${ }^{6}$.

Os módulos 1, 2, 4 e 5 são direcionados aos professores e gestores e possuem conteúdos comuns; o módulo 3 também é direcionado para professores e gestores, entretanto, possui conteúdo específico, subdividindo-se em módulo 3a (para professores) e módulo $3 \mathrm{~b}$ (para gestores).

Após os professores concluírem a Formação Brasil na escola da rede pública de ensino do Município de Campo Limpo Paulista, surgiu a necessidade de propor uma Formação Continuada, com o objetivo de promover a análise de práticas pedagógicas desenvolvidas com o uso do computador portátil e de orientar novas práticas que explorem as possíveis contribuições da tecnologia na aprendizagem.

Além disso, objetiva-se, também, criar a cultura de comunidade de prática, intra e inter instituições, para que o professor vivencie o potencial que as redes têm ao democratizar o diálogo, a cooperação e colaboração solidária na reflexão crítica e construção de conhecimentos.

Para tal, o presente processo de formação foi estruturado com atividades presenciais e acompanhamento dos professores a distância, por meio do Ambiente Colaborativo de Aprendizagem e-Proinfo.

No ambiente e-Proinfo, foi concebida uma comunidade de prática denominada de Formação Continuada, a partir da ferramenta comunidade, com o propósito de fomentar trocas entre professores e equipe de formadores.

\footnotetext{
${ }^{1}$ Disponível em: $<$ http://www.virtual.ufc.br/cursouca/modulo_apropriacao_tec/intro.html $>$

${ }^{2}$ Disponível em: <http://www.virtual.ufc.br/cursouca/modulo_web2/index.html $>$

${ }^{3}$ Disponível em: < http://www.virtual.ufc.br/cursouca/modulo_3/index.html $>$

${ }^{4}$ Disponível em: <http://www.virtual.ufc.br/cursouca/modulo_3b_gestores/intro.html $>$

${ }^{5}$ Disponível em: <http://www.virtual.ufc.br/cursouca/modulo_4_projetos/conteudo/index.html $>$

${ }^{6}$ Disponível em: <http://www.virtual.ufc.br/cursouca/modulo_5/intro.html >
} 
Para a Formação Continuada, os formadores propuseram, inicialmente, um diagnóstico, com o propósito de desvelar aspectos do uso dos materiais didáticos digitais, bem como a apropriação das tecnologias dos professores relacionadas aos aplicativos disponíveis nos computadores portáteis.

Assim, os formadores propuseram duas atividades e utilizaram as seguintes ferramentas no e-Proinfo: enquete e fórum de discussão.

$\mathrm{Na}$ enquete, foi disponibilizada a seguinte proposição: Que tipos de materiais didáticos digitais descritos a seguir você costuma utilizar com seus alunos? Após a proposição, foi listada uma série de materiais didáticos digitais disponíveis no computador portátil: Ferramentas KOffice; Ferramentas Tux; Squeak Etoys; outros.

No fórum de discussão sobre reflexões a respeito da escolha de materiais didáticos digitais, propusemos as seguintes indagações: Como você escolhe os materiais didáticos digitais para utilizar na sua prática pedagógica?

Vale destacar que, para o recorte deste artigo, priorizamos apresentar a proposta inicial de Formação Continuada, que se encontra em processo de construção. Assim como as análises dos resultados desta proposta inicial: a enquete e o fórum de discussão. A seguir, apresentamos as técnicas de coleta de dados.

\subsection{Técnicas de coleta de dados}

Para a coleta quantitativa de dados, foi utilizada, neste trabalho, a enquete, ou questionário com perguntas fechadas.

Para Chizzotti (2009), o questionário é um meio de obter respostas com questões que o próprio informante preenche. Desta forma, a enquete/questionário foi utilizada para identificar quais materiais didáticos digitais do laptop educacional os professores costumam utilizar em sua prática pedagógica.

\subsection{Discurso do sujeito coletivo do fórum de discussão}

Segundo Lefévre e Lefévre (2005), o Discurso do Sujeito Coletivo (DSC) é uma técnica de coleta de dados que resgata o pensamento de uma coletividade elaborando um discurso sobre determinado tema. Para elaborar o pensamento coletivo, é necessário somar qualitativamente pensamentos individuais iguais, agregando elementos que compõem "respostas semelhantes de indivíduos distintos", transformando as respostas em um discurso coletivo com sentido.

Para transformar as respostas em discurso coletivo, são necessárias quatro operações, as quais devem ser realizadas sobre o material coletado, no caso desta pesquisa, os fóruns de discussão: (1) Expressões-Chave; (2) Ideias Centrais; (3) Ancoragens/Categorias (ACs/Cs); (4) DSC propriamente dito.

Para a criação do DSC, nesta pesquisa, foi identificado uma ideia central: (1) critérios de escolha dos materiais didáticos digitais, que serão apresentadas no item 5 , a seguir. 


\section{Resultados}

\subsection{Enquete: Materiais didáticos digitais utilizados pelos professores}

$\mathrm{Na}$ enquete, solicitamos aos participantes que respondessem quais tipos de materiais didáticos digitais do computador portátil costumavam utilizar em suas práticas pedagógicas. A partir das respostas dos professores, foi possível observador que, dos 25 participantes: vinte utilizam o $\mathrm{KW}$ ord $^{7}$ na edição e elaboração de texto (p. ex., contos infantis) com os alunos; cinco fazem uso do Tux Typing ${ }^{8}$ para o aprendizado de digitação com alunos das séries iniciais do Ensino Fundamental I; dez utilizam o Tux Paint ${ }^{9}$ para o aprendizado e a elaboração de pintura com os alunos; dois fazem uso do KolourPaint ${ }^{10}$ para aprendizado e elaboração de desenho com os alunos; 15 professores responderam que fazem uso de outros materiais didáticos digitais, os quais não estão disponíveis no computador portátil, mas sim na Web 2.0, principalmente os materiais didáticos digitais disponibilizados no Portal Aprende Brasil (Tabela 1).

Tabela 1: Tipo de material didático digital utilizado

\begin{tabular}{l|c} 
Tipo de material didático digital & Número de participantes \\
\hline KWord & 20 \\
\hline Tux Typing & 5 \\
\hline Tux Paint & 10 \\
\hline KolourPaint & 2 \\
\hline Outros & 15 \\
\hline
\end{tabular}

\subsection{Fórum de discussão: Escolha de materiais didáticos digitais por professores}

A partir da análise do DSC, foi possível identificar, nos relatos dos professores, avanços nos discursos, durante o processo de formação, ou seja, no decorrer das discussões sobre a escolha de materiais didáticos digitais.

Os professores relataram, inicialmente, que as escolhas dos materiais didáticos digitais visavam contribuir com as atividades propostas, o seu plano de aula e o referencial do município. Em seguida, observamos que os professores passaram a levantar critérios para a escolha dos materiais didáticos digitais. Por fim, além dos relatos sobre a escolha dos materiais didáticos digitais, também identificamos três momentos em que os professores escolhem esses materiais. O discurso coletivo foi o seguinte:

\footnotetext{
${ }^{7}$ KWord é um aplicativo de processamento de texto que faz parte da suíte de escritório KOffice.

${ }^{8}$ Tux Typing é um jogo que incentiva a prática de digitação. O pinguim está com fome e, ao digitar a sequência correta em tempo hábil, ganham-se pontos, alimentando-o com peixes. Existem variações do jogo em que se eliminam meteoritos, que estão prestes a colidir com a cidade. É uma ótima forma de familiarizar com a prática de digitação, de forma gradual e divertida.

9 Tux Paint é um aplicativo para produção de desenhos. Intuitivo, emite um som diferente para cada comando, despertando a curiosidade e incentivando os alunos a descobrirem seus recursos. Também oferece diversas formas geométricas, elementos de cenário para desenhos livres, diversos tipos de pincéis, reflexões e rotações.

${ }^{10} \mathrm{O}$ KolourPaint é um editor de imagens, muito próximo do paint, do Windows, utilizado para fazer desenhos ou alterações em imagens.
} 
Primeiramente eu escolhia os materiais que pudessem contribuir para com meu Plano de Aula e com o referencial, atrelando o uso do computador portátil e suas ferramentas. Após as discussões na formação, percebo o quanto estava enganado. Não tenho que procurar algo para atender às minhas necessidades, tenho que escolher um material que desperte o interesse do aluno. Além dessa reflexão, observei também que escolho os matérias em três momentos: o primeiro momento foi na elaboração do Plano de Aula, no início do ano letivo; o segundo momento aconteceu durante a utilização em sala de aula com os alunos; e o terceiro, e último momento, após a utilização do material em sala de aula. Acredito que a reflexão proposta é bastante interessante e nos abre um leque para repensar que muitas vezes ao fazer a escolha de um material digital, nem sempre ocorre uma avaliação crítica, além de essa escolha acontecer em diferentes momentos.

\section{Considerações}

A partir do processo realizado, foi possível verificar que criação da comunidade de prática requer a diminuição de fronteiras, e a necessidade de aprender a ouvir cuidadosamente o outro. Ficou evidente que o trabalho em equipe é fundamental para que a colaboração se efetive dentro da comunidade de prática.

Conforme Hargreas (2000, p. 106), "trabalhar com parceria é quase como pensar que se têm dois cérebros". O processo de criação da rede colaborativa destacou que, no trabalho em colaboração, a tomada de decisão deve ser distribuída entre os participantes. Houve percepção de que não há uma autoridade central, neste caso, há um sentido do fazer coletivo (JOHN-STEINER, 2000).

Durante a realização das atividades no ambiente e-Proinfo, foram propiciadas, aos professores, atividades que permitiram a retomada de aspectos da formação inicial, bem como promovidas atividades em que puderam refletir sobre a escolha de materiais didáticos digitais. Isso proporcionou mais segurança aos professores no sentido de compartilharem suas práticas com o uso dos computadores portáteis dentro e fora da escola.

Por fim, em todo o estudo, notou-se um grande esforço da equipe de formadores, bem como da equipe gestora e dos professores para a criação da comunidade de prática, assim como para a discussão sobre a escolha de materiais didáticos digitais disponíveis no computador portátil e na Web 2.0.

Com base nesta proposta de escolha de material didático digital, por professores, em uma comunidade de prática, o desdobramento desta pesquisa envolve duas ações: (1) elaborar um plano detalhado de Formação Continuada em comunidades de prática; (2) ampliar a discussão sobre a escolha de material didático digital na formação dos professores, para que, por meio da escolha de critérios pedagógicos, o professor tenha fundamentos para identificar as potencialidades e decidir qual material didático digital escolher para integrar ao currículo e à sala de aula, com seus alunos. 


\section{Referências}

ASHTON, P.,WEBB, R. Making a difference: teachers' sense of efficacy and student achievement. New York: Longman, 1986.

BRASIL. Cartilha digital do programa um computador por aluno - prouca. Brasília: MEC, 2010.

CHIZZOTTI, A. Pesquisa em ciências humanas e sociais. São Paulo: Cortez, 2009.

COMASSETTO, L. S. Novos espaços virtuais para o ensino e a aprendizagem a distância: estudo da aplicabilidade dos desenhos pedagógicos. Tese (Doutorado) Programa de Pós-Graduação em Engenharia de Produção, Universidade Federal de Santa Catarina (UFSC), Florianópolis/SC, 2006.

GODOI, K. A.; PADOVANI, S. Estudo analítico de checklists para avaliação de software educativo. In: ULBRICHT, V. R.; CYBIS, A. T. (Orgs.). Hipermídia: desafios da atualidade. Florianópolis: Pandion, 2009.

HARGREAS, A. A escola como organização aprendente: buscando uma educação de qualidade. Porto Alegre: Artes Médicas Sul, 2000.

HOMANS, P. The group effect: social cohesion and health outcomes. Chicago, 2009.

HORTON, W. Designing web-based training. US: John Wiley \& Sons, 2000.

JOHN-STEINER, V. Creative collaboration. New York: Oxford University Press, 2000.

LEFEVRE, F.; LEFEVRE, A. M. C. Depoimentos e discursos: uma

proposta de análise em pesquisa social. Brasília: Líber Livro Editora, 2005.

LYRA, A.; LEITÃO, D. A.; AMORIM, G. B. C. de; GOMES, A. S. Ambiente virtual para análise de software educativo. WIE 2003 WORKSHOP BRASILEIRO DE INFORMÁTICA EDUCATIVA, 2003, Campinas.

MILANI, E. A informática e a comunicação matemática. In: SMOLE, K. S.; Diniz, M. I. (orgs.). Ler, escrever e resolver problemas: habilidades básicas para aprender matemática. Porto Alegre: Artmed, 2001. p. 176-200.

PARÂMETROS curriculares nacionais. Terceiro e quarto ciclos do ensino fundamental: introdução aos parâmetros nacionais. Secretaria de Educação Fundamental. Brasília: MEC/SEF, 1998.

PROINFO - Programa Nacional de Informática na Educação. Checklist. ENCONTRO NACIONAL DO PROINFO, 3. Disponível em: < http://www2.uel.br/seed/nte/analisedesoftwares.html>. Acesso em: out. 2007.

SCHROCK, K. Software evaluation form. 2000. Disponível em: < http://courses.csusm.edu/educ422dh/wordfiles/Software\%20Evaluation\%20Form.doc $>$ Acesso em: out. 2007.

TEDESCO, J. C. Educação e novas tecnologias: esperança e incerteza. São Paulo: Cortez, 2004. 
WENGER, E. Communities of practice the social fabric of a learning organization. Healthcare Forum Journal. Chicago/USA, July-August, 1996. Disponível em: $<$ http://www.ewenger.com/pub/pubhealthcareforum.htm>. Acesso em: 20 fev. 2010.

Communities of practice - learning, meaning and identity. Cambridge: Cambridge University Press. 1998.

SYNEDER, W. Communities of practice: the organizational frontier a new business management aid. Harvard Business Revew, 78 (1) 139-147.

WENGER, E.; McDermott, R.; Snyder, W. Cultivating communities of practice. Boston: Harvard Business School Press,2002.

UNESCO. Padrões de competências em TIC para professores. Organização das Nações Unidas para a Educação, a Ciência e a Cultura, 2008. Disponível em: $<$ http://www.brasilia.unesco.org/publicacoes/livros/padroes_competencia_tics_profes sores> Acesso em: ago. 2009. 